\title{
Clinical effectiveness of dolutegravir in the treatment of HIVIAIDS
}

\author{
This article was published in the following Dove Press journal: \\ Infection and Drug Resistance \\ I October 2015 \\ Number of times this article has been viewed
}

\author{
Huda Taha' \\ Archik Das ${ }^{2}$ \\ Satyajit Das ${ }^{1,3}$ \\ 'Integrated Sexual Health Service \\ Coventry and Warwickshire \\ Partnership NHS Trust, Coventry, \\ ${ }^{2}$ School of Medicine, Birmingham \\ University, Birmingham, ${ }^{3}$ Coventry \\ University, Coventry, UK
}

Correspondence: Satyajit Das Integrated Sexual Health Service, Coventry and Warwickshire Partnership NHS Trust, 3rd Floor, City of Coventry Health Center, Stoney Stanton Road, Coventry CVI 4FS, UK

Email satyajit.das@covwarkpt.nhs.uk
Abstract: Dolutegravir (DTG) is a second-generation integrase strand transfer inhibitor (INSTI), which has now been licensed to be used in different countries including the UK. Earlier studies have demonstrated that DTG when used with nucleoside backbone in treatment-naïve and -experienced patients has been well tolerated and demonstrated virological suppression comparable to other INSTIs and superiority against other first-line agents, including efavirenz and boosted protease inhibitors. Like other INSTIs, DTG uses separate metabolic pathways compared to other antiretrovirals and is a minor substrate for CYP-450. It does not appear to have a significant interaction with drugs, which uses the CYP-450 system. Nonetheless, it uses renal solute transporters that may potentially inhibit the transport of other drugs and can have an effect on the elimination of other drugs. However, the impact of this mechanism appears to be very minimal and insignificant clinically. The side effect profiles of DTG are similar to raltegravir and have been found to be well tolerated. DTG has a long plasma half-life and is suitable for once daily use without the need for a boosting agent. DTG has all the potential to be used as a first-line drug in combination with other nucleoside backbones, especially in the form of a single tablet in combination with abacavir and lamivudine. The purpose of this review article is to present the summary of the available key information about the clinical usefulness of DTG in the treatment of HIV infection.

Keywords: dolutegravir, integrase inhibitors, HIV, antiretroviral, treatment

\section{Introduction}

The treatment of HIV infection is complex and changes rapidly as advances are made in basic science and clinical experience. Understanding of the different stages of viral replication and different enzymes used by the virus for their replication have helped to identify different agents that can block the function of the enzymes and thereby stop the viral replication inside host cells. Various events in the HIV life cycle plus host factors have been identified as potential targets for antiretroviral therapy. ${ }^{1,2}$ The complexity of treatment regimens against HIV infection increases further with the rising number of available compounds and the growth in new information about their use.

Drugs of five different classes are currently available in the developed world, with several others close to release. Inhibitors of HIV reverse transcriptase and of HIV protease are so far the most developed and most commonly used in clinical practice. ${ }^{3}$

Newer agents of these classes with better efficacy against the virus and sustained activity against viral resistance are in the pipeline of development. Drugs with longer half-life that penetrate in to different body compartments with less systemic side effects to the host are coming into production. ${ }^{4}$ Drugs with higher antiviral potency, 
less side effects, and simpler tablet regimens could improve the long-term treatment adherence and longer survival. ${ }^{5}$

Integrase (IN) has been a target for the drug development for sometime. ${ }^{6}$ Integrase strand transfer inhibitors (INSTIs) are one of the five classes of drugs and have demonstrated a potent antiviral activity ${ }^{7}$ and a noninferior efficacy versus regimens containing boosted protease inhibitors (PIs) or nonnucleoside reverse transcriptase inhibitors (NNRTIs) in treatment-naïve patients. INSTI-based regimens are among preferred options for first-line therapy for individuals with HIV-1 infection. Raltegravir (RAL), elvitegravir (EVG), and dolutegravir (DTG) all target the strand transfer step of viral DNA integration and are referred to as INSTI drugs. These are considered to be first line of treatment options in the Europe and the US. ${ }^{6}$

\section{Dolutegravir - pharmacology, mode of action, and pharmacokinetics}

DTG is a nitrogen-containing polycyclic compound possessing amide functionality and has two chiral centers, providing potential for stereoisomerism. ${ }^{8}$ It has been derived from the patent drug S/GSK1265744, which has one long-acting injecting formulation and an oral formulation developed as DTG. ${ }^{9}$

\section{Mode of action}

It is well known that integrase inhibitors (INTs, also known as integrase strand transfer inhibitors or INSTIs) represent a relatively new class of antiretroviral drugs to treat HIV-1 infection. It inhibits the incorporation of HIV-1 proviral DNA into the host cell genome, a step that is vital for viral replication. HIV IN is a $32 \mathrm{kDa}$ protein that consists of three distinct structural and functional domains: the N-terminal domain, the catalytic core domain, and the C-terminal domain. It is the highly conserved catalytic triad, known as D64D116E152, which is believed to be responsible for the enzymatic activity. ${ }^{10}$

This enzyme catalyzes two vital chemical reactions known as $3^{\prime}$ processing and strand transfer. During the first of the two steps, IN cleaves two terminal nucleotides from the $3^{\prime}$ ends of both of the viral DNA strands to expose the invariant CA 3'-OH DNA ends. During the ensuing strand transfer step, IN is responsible for catalyzing the integration of viral DNA into the chromatin network of the host cell, using the freshly exposed $3^{\prime}-\mathrm{OH}$ ends to attack the phosphodiesterase backbone of the host cell DNA.9,10

DTG inhibits the HIV IN by binding to the IN active site and blocking the strand transfer step of HIV DNA integration.
It fits loosely into the binding pocket of the intasome and undergoes conformational changes in the pocket structure while retaining its binding ability. The ability to make adjustment in the binding capacity is potentially favorable compared to other INSTIs. ${ }^{11,12}$

\section{Pharmacokinetics}

DTG has favorable pharmacokinetic properties and retains plasma concentrations well above the protein-adjusted $90 \%$ inhibitory concentration (IC90) for HIV-1.11,13

\section{Absorption}

DTG is rapidly absorbed following oral administration. The median maximum plasma concentration $\left(C_{\max }\right)$ is achieved 1.5-2.5 hours after oral intake with a mean half-life of 12-15 hours, rendering feasible for once-daily dosing without the need for pharmacological boosting. Bioavailability varies with fat content. Song et $\mathrm{al}^{14}$ demonstrated that food intake increased DTG exposure and reduced the rate of absorption. Healthy subjects received DTG (50 mg) in a single-dose crossover study while they were in the fasted state or with low-, moderate-, or high-fat meals. The area under the plasma concentration-time curve (AUC) from 0 hour to infinity hours increased by $33 \%, 41 \%$, and $66 \%$ when administered with low-, moderate-, or high-fat meals, respectively, compared with the fasting state. However, the increase in DTG exposure is not expected to impact clinical safety and, thus, can be taken with or without food and without considering the fat content of the food. ${ }^{11,14}$

\section{Distribution}

DTG has got high affinity for plasma proteins, and $>99 \%$ of DTG is bound to plasma proteins, and it is independent of the plasma concentration. DTG has good penetration to other body compartments and appears to cross the blood-brain barrier; however, clinical outcomes have not been determined. The apparent volume distribution of DTG following oral absorption appears to be around over 12.5 L, which is comparable to the level seen after intravenous administration. This in turn suggests that the drug has a very low first-pass metabolism. ${ }^{13}$ DTG is present in other body compartments, including cerebrospinal fluid and cervicovaginal fluid. After oral dosing, DTG exposure in cervicovaginal fluid was found to be $5 \%-7 \%$ of blood plasma exposure compared to around $200 \%$ for RAL. In semen, the DTG concentration is $6 \%-7 \%$ of blood plasma concentration compared to over $400 \%$ of ritonavir (RTV). The exposure in colorectal tissue is $18 \%-20 \%$ of the blood 
plasma concentration. It could be due to the fact that DTG is highly protein bound, and the amount of free drug present may be adequate and comparable to in vitro IC90. DTG exposure in cerebrospinal fluid was similar to unbound plasma concentrations in blood plasma. ${ }^{11,13}$

\section{Metabolism}

DTG is extensively metabolized in the liver using the Phase II metabolism primarily through glucuronidation via UGT1A1, while a minor pathway (in Phase I) involves CYP450 3A4 (CYP3A4) with other minor pathways (Phase II) involving UGT1A3 and GT1A9. ${ }^{15}$

\section{Elimination}

The terminal half-life is about 14 hours. The apparent oral clearance is about $1 \mathrm{~L} / \mathrm{h}$. Fifty-three percent of the total oral dose of DTG is excreted unchanged in the feces, $32 \%$ through urine as glucuronide (18\%) or alkylated product $(3.5 \%)$, and other organic conjugated products resulting from Phase II liver metabolisms. About 1\% of unchanged DTG is excreted through urine, rendering it relatively safer to use in mild or moderate renal impairment. ${ }^{15}$

\section{Dolutegravir - clinically significant drug interactions}

DTG has the potential to interact with other medicinal products, including antiretrovirals, but they appear to be clinically insignificant in most of the cases. ${ }^{15,16}$ DTG is metabolized by the uridine diphosphate glucuronosyltransferase (UGT) enzyme system (Phase II liver metabolism). ${ }^{17}$ Coadministration of drugs or medicinal agents that use UGT1A1, UGT1A3, and UGT1A9 may alter the blood level of DTG, and some of the interactions may have clinical implications (Table 1). ${ }^{11,17}$

DTG is a minor substrate for the CYP-P450 system (Phase 1 metabolism); however, this could potentially be altered when used along with drugs that has major effect on CYP-450 system, especially CYP-45 3A4.

Coadministration with drugs using $p$-glycoprotein and breast cancer resistance protein may alter the blood level of DTG as well but no clinically significant interaction has been reported. DTG uses the organic cation transporter (OCT) system in renal tubules and can increase the blood level of OCT2-dependent drugs. ${ }^{18}$ DTG and the pharmacological booster cobicistat are the two examples of well-characterized

Table I Key drug interactions of dolutegravir

\begin{tabular}{|c|c|c|c|}
\hline Interacting drug class & $\begin{array}{l}\text { Interacting } \\
\text { drug }\end{array}$ & $\begin{array}{l}\text { Effect on dolutegravir or interacting } \\
\text { drug concentration }\end{array}$ & Dose recommendation \\
\hline \multicolumn{4}{|l|}{ Antiretrovirals } \\
\hline NRTls & TDF & No significant effect was observed & No change in dose \\
\hline \multirow[t]{3}{*}{ NNRTIs } & $\mathrm{EFV}$ & $\begin{array}{l}\text { Significant reduction in DTG plasma } \\
\text { concentration }\end{array}$ & $\begin{array}{l}\text { Increase dose of DTG to } 50 \mathrm{mg} \\
\text { twice daily }\end{array}$ \\
\hline & ETR & $\begin{array}{l}\text { Significant reduction in DTG plasma } \\
\text { concentration }\end{array}$ & $\begin{array}{l}\text { Do not administer DTG with ETR } \\
\text { alone }\end{array}$ \\
\hline & ETR/DRV/RTV & No significant effect was observed & $\begin{array}{l}D T G \text { and ETR can be used only } \\
\text { if } D R V / r \text { is also included in the } \\
\text { regimen }\end{array}$ \\
\hline Pls & $\mathrm{ATV} / \mathrm{r}$ & Increase in DTG plasma concentration & No change in dose \\
\hline \multicolumn{4}{|l|}{ Acid-reducing agents } \\
\hline $\begin{array}{l}\text { Bivalent cations including calcium, } \\
\text { iron, or zinc supplements, or with } \\
\text { vitamin-D supplements }\end{array}$ & & $\begin{array}{l}\text { Significant reduction in DTG plasma } \\
\text { concentration, but no interaction } \\
\text { with PPI }\end{array}$ & $\begin{array}{l}\text { Administer antacids or bivalent } \\
\text { containing supplements } 2 \mathrm{~h} \text { after or } \\
6 \mathrm{~h} \text { before DTG dosing }\end{array}$ \\
\hline \multicolumn{4}{|l|}{ Antituberculous agents } \\
\hline & RIF & $\begin{array}{l}\text { Significant reduction in DTG plasma } \\
\text { concentration }\end{array}$ & $\begin{array}{l}\text { Increase the DTG dosing frequency } \\
\text { to } 50 \mathrm{mg} \text { twice daily }\end{array}$ \\
\hline & RBT & No significant effect was observed & No change in dose \\
\hline \multicolumn{4}{|l|}{ Oral contraceptives } \\
\hline Ortho-cyclen & & No significant effect was observed & No change in dose \\
\hline \multicolumn{4}{|l|}{ Antihepatitis $C$ virus agents } \\
\hline \multirow[t]{2}{*}{ Pls } & $\mathrm{BCV}$ & No significant effect was observed & No change in dose \\
\hline & TRV & No significant effect was observed & No change in dose \\
\hline \multicolumn{4}{|l|}{ Opioid agonist } \\
\hline & Methadone & No significant effect was observed & No change in dose \\
\hline
\end{tabular}

Note: Data from the following studies. ${ }^{11,16,18,21,22,25,39,40}$

Abbreviations: ATV/r, atazanvir/ritonavir; BCV, boceprevir; DTG, dolutegravir; DRV/RTV, darunavir/ritonavir; EFV, efavirenz; ETR, etravirine; h, hour; NNRTIs, nonnucleoside reverse transcriptase inhibitors; NRTIs, nucleoside reverse transcriptase inhibitors; Pls, protease inhibitors; RBT, rifabutin; RIF, rifampin; TDF, tenofovir disoproxil fumarate; TRV, telaprevir. 
mechanisms of creatinine transporter inhibition in the proximal tubule. While DTG inhibits mainly the renal transporter OCT2 in the basolateral membrane of the proximal tubular cell, cobicistat predominantly inhibits the renal transporter MATE1 in the luminal membrane, ${ }^{18-20}$ thereby increasing the blood level of creatinine without impairing the true glomerular filtration rate. DTG can interact with oral medicinal agents, such as antacids containing bivalent cations, and the interaction of DTG with bivalent cations ${ }^{21}$ appears to be physical in the form of chelation and, hence, can reduce the blood level of DTG (Table 1).

\section{Interaction with specific groups}

\section{Antiretrovirals}

Similar to RAL, DTG is metabolized primarily by UGT1A1, so the number and type of drug-drug interactions (DDIs) are expected to be comparable to those seen with RAL. ${ }^{11}$

Drug interaction between nucleos $(\mathrm{t})$ ide reverse transcriptase inhibitors (NRTIs) and DTG is very minimum and clinically insignificant. ${ }^{11}$ Tenofovir disoproxil fumarate (TDF), a NRTI that is primarily eliminated by renal mechanisms, does not have any significant interactions with DTG, and these two drugs can be taken together without dose adjustment (Table 1).

Because NNRTIs display a complicated interaction outline and have the potential to induce both the major and minor metabolic pathways of DTG, one would expect a reduced DTG plasma concentration if these drugs were coadministered. ${ }^{22,23}$ When DTG is combined with efavirenz (EFV), there is a decrease in AUC, $C_{\max }$, trough plasma concentration $\left(C_{\text {trough }}\right)$ by $57 \%, 39 \%, 75 \%$, respectively, hence, the recommended dose of DTG is $50 \mathrm{mg}$ twice daily when coadministered with EFV. $^{23}$

When DTG was combined with etravirine (ETR) in healthy volunteers, ETR significantly decreased exposures of DTG (AUC and $C_{\text {trough }}$ was decreased by $70 \%$ and $88 \%$, respectively). ${ }^{24}$ When ETR was combined with a RTVboosted PI, the interaction was reversed. But ETR/lopinavir (LPV)/RTV treatment had no effect on the DTG plasma $\mathrm{AUC}_{0}-$ and $C_{\text {max }}$, whereas the plasma concentration increased by $28 \%$. Combination of ETR/darunavir (DRV)/RTV modestly decreased the plasma DTG $\mathrm{AUC}_{0}-, C_{\max }$, and plasma concentration by $25 \%, 12 \%$, and $37 \%$, respectively. ${ }^{25,26}$ Such effects of ETR/LPV/RTV and ETR/DRV/RTV do not appear to have any clinical relevance. ${ }^{24}$ The combination of DTG and ETR alone should be avoided, but it may be coadministered with ETR without a dose adjustment if DTG and boosted PIs is concurrently administered. ${ }^{24}$
Coadministration of DTG with boosted PIs has been studied in randomized trials, and data demonstrate that DTG can be coadministered with PIs without dose adjustment. DTG was combined with atazanavir (ATV)/RTV and ATV in a randomized, open-label, two period's crossover study in healthy adults. The results showed modest, nonclinically significant increase in DTG exposure (Table 1). But no dose adjustment for DTG was required when coadministered with ATV and ATV/RTV, and it was well tolerated. ${ }^{27}$

Similarly, when DTG was coadministrated with LPV/ RTV there was no clinically significant effect on the steadystate plasma concentration of DTG and again it showed good tolerability (Table 1). Although coadministration of DRV/RTV resulted in decreased steady-state plasma DTG exposures, the effect is not anticipated to be of clinical significance. ${ }^{26}$

\section{Antacids, calcium, and iron supplements}

Polyvalent cations, particularly bivalent cations, including calcium, iron, or zinc supplements as well as other cations present in antacids, it may chelate DTG and reduce its efficacy. ${ }^{21,28}$ Administering antacids at the same time with DTG lowers DTG AUC and minimum plasma concentration $\left(C_{\min }\right)$ by $74 \%$. To evade this interaction, DTG should be given at least 2 hours before or 6 hours after administering polyvalent cations (Table 1). Gastric $\mathrm{pH}$ does not seem to have any effect on DTG absorption and is not known to have any interaction between DTG and proton pump inhibitors. $^{21,22}$

\section{Rifamycin compounds}

Rifampin (RIF) is a potent inducer of CYP450 (3A4) and UGT1A1. RIF (600 mg) lowers DTG AUC and $C_{\min }$ by $54 \%$ and $72 \%$, respectively; administering RIF with $50 \mathrm{mg}$ of DTG twice daily results in DTG levels that are comparable to those seen when DTG is dosed at $50 \mathrm{mg}$ once daily without concomitant RIF (Table 1). Therefore, the DTG dosage should be increased to $50 \mathrm{mg}$ twice daily for IN-naïve patients receiving concomitant $\mathrm{RIF}^{29}$

Rifabutin (RBT) lowers DTG $C_{\min }$ by $30 \%$ but does not significantly change the AUC or $C_{\max }$. Based on these data, RBT (300 mg once daily) may be coadministered with $50 \mathrm{mg}$ of DTG once daily. ${ }^{29}$

\section{Direct-acting hepatitis $C$ virus antivirals}

Use of boceprevir (BCV) and telaprevir (TRV) with DTG has been investigated in healthy volunteers in an open-label study. Coadministration of BCV (800 mg every 8 hours) and DTG 
(50 mg once daily) increased DTG $C_{\max }, \mathrm{AUC}$, and $C_{\text {trough }}$ by $5 \%, 7 \%$, and $8 \%$, respectively. This interaction is of no clinical significance (Table 1). Similarly, TRV increased DTG AUC, $C_{\max }$, and $C_{\text {trough }}$ by $25 \%, 19 \%$, and $37 \%$, respectively, by the inhibition of CYP3A. When compared to historical controls, there was no effect on TRV exposure. Hence, no dose adjustment is necessary when DTG is combined with direct-acting antivirals. ${ }^{30}$ DTG has not been found to have any significant interaction with grazoprevir and elbasvir, newer antivirals for treating hepatitis $\mathrm{C}$ virus. ${ }^{31}$

\section{Other agents}

DTG may be given with estrogen/progestin oral contraceptives without dose adjustment and was well tolerated when combined with these compounds (Table 1). ${ }^{32}$

Available data ${ }^{8,11}$ does not support any possibility for DTG to cause clinically significant DDIs with 3-hydroxy-3methyl-glutaryl-co-enzyme A reductase inhibitors such as simvastatin, rosuvastatin, and atorvastatin.

Dofetilide is a class III antiarrhythmic agent (available in the US in capsules containing $125 \mu \mathrm{g}, 250 \mu \mathrm{g}$, and $500 \mu \mathrm{g}$ of dofetilide and not available in Europe and Australia) has the potential to interact with DTG. ${ }^{33-35}$ The use of DTG can increase dofetilide level or affect by inhibiting the renal OCT2, and thereby increasing the blood level of dofetilide. There is a risk of life-threatening arrhythmias when DTG is used with dofetilide, and hence, coadministration of these two drugs is contraindicated. ${ }^{33,36}$ Coadministration of DTG and metformin was well tolerated. In a study using healthy volunteers, coadministration of DTG and metformin was well tolerated, but significantly increased metformin plasma exposure, and the effects were DTG dose dependent. Although metformin has a wide therapeutic index and alone is not associated with hypoglycemia, close monitoring is recommended when coadministering metformin and DTG. ${ }^{37}$

DTG and prednisone coadministration was well tolerated. No dose adjustment is essential for DTG when coadministered with prednisone. ${ }^{8,38,39}$ DTG can be taken with or without food in treatment-naïve and INSTI-naïve patients. However, in treatment-experienced patients in the presence of INSTI class resistance, DTG should preferably be taken with food to enhance the exposure. ${ }^{14}$ Methadone use has not been found to have any interaction with DTG and dose adjustment for methadone or DTG is not recommended. ${ }^{40}$

\section{Efficacy studies of dolutegravir}

DTG use has been studied in HIV treatment-naïve and experienced patients and the results are mostly very much favorable, standing it relatively ahead of other antiretrovirals (Table 2). In SPRING-1, ${ }^{41}$ a treatment-naïve, Phase IIb randomized dose-ranging multicenter, partially blinded study, DTG demonstrated sustained efficacy and a favorable safety and tolerability profile. In this study, adults with HIV-1 infection who were treatment-naïve were randomized to DTG $10 \mathrm{mg}, 25 \mathrm{mg}$, or $50 \mathrm{mg}$ once daily or $600 \mathrm{mg}$ of EFV once daily (control arm) combined with investigator-selected dual nucleos(t)ide reverse transcriptase inhibitor (NRTI), backbone regimen TDF/emtricitabine (TDF/FTC), or ABC/3TC. The primary goal of SPRING-1 was to select a DTG dose for Phase III development. A rapid and sustained antiviral response was detected across all DTG doses, with $82 \%$ of all participants who received DTG attaining plasma HIV-1 RNA $<50$ copies/mL through week 96 . The safety profile of DTG at 96 weeks was favorable, with no dose-response relationship with adverse events (AEs). Tolerability, in general, was also better with DTG in comparison with EFV. There was no protocol-defined virological failure in participants receiving $50 \mathrm{mg}$ of DTG or resistance mutations to INSTIs or NRTIs, and the $50 \mathrm{mg}$ dose was selected for Phase III evaluation. DTG demonstrated a sustained efficacy and a favorable safety and tolerability profile in a treatment-naïve Phase IIb randomized dose-ranging multicenter, partially blinded study.

The SINGLE study, ${ }^{42}$ a head-to-head randomized, doubleblind, Phase III study comprised treatment-naïve adults with HIV-1 infection, and the participants were allocated to DTG $50 \mathrm{mg}$ combined with $\mathrm{ABC} / 3 \mathrm{TC}$ once daily or in combination therapy with single pill Atripla containing TDF, FTC, EFV once daily. At 48 weeks, $88 \%$ of the DTG group achieved viral load suppression $<50$ copies $/ \mathrm{mL}$, in comparison to $81 \%$ suppression in the Atripla group. Statistical analysis demonstrated that the DTG regimen performed significantly better than Atripla $(P=0.003)$ and met the criterion for statistical superiority. Virological failure was $4 \%$ in both arms. Results were similar for participants with different baseline viral load levels (above or below 100,000 copies/mL). The DTG regimen was associated with a significantly higher rise in CD4 cells compared to the Atripla group (267 cells $/ \mathrm{mm}^{3}$ vs 208 cells $/ \mathrm{mm}^{3}$, respectively, $\left.P<0.001\right)$. Differences in efficacy were primarily driven by a lower rate of discontinuation due to AEs for the DTG plus ABC/3TC arm and were independent of baseline viral load. Treatment-related discontinuation was $2 \%$ in the DTG arm compared to $10 \%$ in the EFV arm. The safety profile of the DTG arm in general was more favorable when compared to the Atripla arm. No patients in the DTG arm developed INSTI or NRTI resistance, whereas 
Table 2 Key efficacy studies of dolutegravir

\begin{tabular}{|c|c|c|c|c|c|c|}
\hline Naïve studies & $\begin{array}{l}\text { Participants } \\
\text { (N) }\end{array}$ & Design & Duration & Comparing arm & $\begin{array}{l}\text { VL }<\mathbf{5 0} \\
(\%)\end{array}$ & Conclusion \\
\hline $\mathrm{SINGLE}^{42}$ & 844 & $\begin{array}{l}\text { Randomized } \\
\text { I:I }\end{array}$ & 144 wk & $\begin{array}{l}\text { DTG } 50 \mathrm{mg}+\mathrm{ABC} / 3 \mathrm{TC} \\
\mathrm{EFV} / \mathrm{FTC} / \mathrm{TDF}\end{array}$ & $\begin{array}{l}80 \% \\
72 \%\end{array}$ & $\begin{array}{l}\text { DTG superior to EFV } \\
\text { No treatment-emergent } \\
\text { resistance in DTG arm }\end{array}$ \\
\hline SPRING-2 ${ }^{43}$ & 822 & $\begin{array}{l}\text { Randomized } \\
I: I\end{array}$ & $96 \mathrm{wk}$ & $\begin{array}{l}\text { DTG } 50 \mathrm{mg}+\text { two NRTls } \\
\text { RAL } 400 \mathrm{mg} \text { BD + two } \\
\text { NRTls }\end{array}$ & $\begin{array}{l}81 \% \\
76 \%\end{array}$ & $\begin{array}{l}\text { DTG was noninferior to RAL } \\
\text { No additional resistance to } \\
\text { INSTIs or NRTIs since week } 48 \\
\text { in DTG arm }\end{array}$ \\
\hline FLAMINGO ${ }^{45}$ & 484 & $\begin{array}{l}\text { Randomized } \\
\text { I:I }\end{array}$ & 96 wk & $\begin{array}{l}\text { DTG } 50 \mathrm{mg}+\text { two NRTIs } \\
\text { DRV/RTV + two NRTls }\end{array}$ & $\begin{array}{l}82 \% \\
52 \%\end{array}$ & $\begin{array}{l}\text { DTG superior to DRV/RTV } \\
\text { at } 96 \text { wk. Difference most } \\
\text { pronounced at baseline VL } \\
>100,000 \text { copies } / \mathrm{mL}\end{array}$ \\
\hline \multicolumn{7}{|c|}{ Experienced studies } \\
\hline SAILING ${ }^{46}$ & 715 & $\begin{array}{l}\text { Randomized } \\
\text { I:I }\end{array}$ & $48 w k$ & $\begin{array}{l}\text { DTG } 50 \mathrm{mg}+\text { two NRTIs } \\
\text { RAL } 400 \mathrm{mg} \text { BD + NRTls }\end{array}$ & $\begin{array}{l}71 \% \\
64 \%\end{array}$ & $\begin{array}{l}\text { Treatment-emergent INSTIs } \\
\text { resistance (four in DTG arm) vs } \\
\text { (I7 in RAL arm). } \\
\text { DTG superior to RAL ( } P=0.03 \text { ). }\end{array}$ \\
\hline VIKING-348 & 183 & $\begin{array}{l}\text { Single-arm } \\
\text { study }\end{array}$ & $24 \mathrm{wk}$ & $\begin{array}{l}\text { DTG } 50 \mathrm{mg} \text { BD + (continuing } \\
\text { a failing regimen [without } \\
\text { RAL or EVG] } 7 \text { days) } \\
\text { optimized } \geq \text { I fully active } \\
\text { drug and DTG continued }\end{array}$ & $69 \%$ & $\begin{array}{l}\text { Reduced response with QI48 + } \\
\geq 2 \text { resistance mutations } \\
\text { DTG } 50 \mathrm{mg} \text { BD-based therapy } \\
\text { was effective in highly treatment } \\
\text { experience with INSTI-resistance }\end{array}$ \\
\hline VIKING-4 ${ }^{49}$ & 30 & $\begin{array}{l}\text { Randomized } \\
\text { I:I }\end{array}$ & $24 \mathrm{wk}$ & $\begin{array}{l}\text { DTG } 50 \text { mg BD, } 7 \text { days on } \\
\text { failing regimen without RAL } \\
\text { or EVG vs placebo DTG }\end{array}$ & $\begin{array}{l}40 \% \text { no } \\
\text { drop }\end{array}$ & $\begin{array}{l}\text { DTG } 50 \mathrm{mg} \text { BD-based therapy } \\
\text { was effective in INSTI failing } \\
\text { regimen }\end{array}$ \\
\hline
\end{tabular}

Abbreviations: ABC/3TC, abacavir/lamivudine; DRV/RTV, darunavir/ritonavir; DTG, dolutegravir; EFV, efavirenz; EVG, elvitegravir; FTC, emtricitabine; INSTIs, integrase strand transfer inhibitors; NRTIs, nucleoside reverse transcriptase inhibitors; RAL, raltegravir; 3TC, lamivudine; TDF, tenofovir disoproxil fumarate; wk, weeks; VL, viral load; BD, twice a day.

one patient on Atripla developed NRTI resistance and four patients developed NNRTI resistance. ${ }^{42}$

At 96 weeks of follow-up, DTG plus ABC/3TC remained superior to EFV/TDF/FTC. No major treatment-emergent INSTI or NRTI resistance mutations were detected through 96 weeks with DTG plus ABC/3TC. In this study, $50 \mathrm{mg}$ of DTG combined with $\mathrm{ABC}$ and $3 \mathrm{TC}$ once daily as a single pill was superior to single pill Atripla in treatment-naïve HIV-1 patients. ${ }^{42}$

In SPRING-2, ${ }^{43}$ a 96-week, Phase III, randomized, doubleblind, active-controlled, noninferiority study, treatment-naïve adults with HIV-1 infection were randomly assigned (1:1) to receive either DTG (50 mg) once daily or RAL (400 mg) twice daily. Study drugs were given with coformulated TDF/ FTC or ABC/3TC. The primary endpoint was the proportion of participants with HIV-1 RNA $<50$ copies/mL at 48 weeks, with a $10 \%$ noninferiority margin. ${ }^{43}$

The primary analysis of the SPRING-2 study ${ }^{43}$ at week 48 demonstrated that $88 \%$ of patients in the DTG arm achieved an HIV-1 RNA of $<50$ copies/mL compared to $85 \%$ in the RAL arm (adjusted difference 2.5\%; 95\% CI: -2.2 to 7.1 ). AEs were similar between the two treatment groups. There was no evidence of treatment-emergent resistance in patients with virological failure on DTG, whereas for the patients with virological failure who received RAL, one had INSTI treatment-emergent resistance and four had NRTI treatment-emergent resistance. DTG has a noninferior efficacy and similar safety profile compared to RAL. ${ }^{43}$ At week 96 analysis in SPRING-2 study, once-daily DTG was noninferior to the twice-daily RAL arm with $81 \%$ of patients in the DTG arm and $76 \%$ of patients in the RAL arm having HIV-1 RNA $<50$ copies/ $\mathrm{mL}$ (adjusted difference $4.5 \%, 95 \% \mathrm{CI}:-1.1 \%$ to $10.0 \%$ ) and confirmed noninferiority. Median increases in CD4 cell count from baseline were similar between the groups (276 cells $/ \mu \mathrm{L}$ for DTG and 264 cells/ $\mu \mathrm{L}$ for RAL). No study-related serious AEs occurred between week 48 and week 96. Ten patients in each group discontinued because of AEs. In those who had virological failure, no additional resistance to INSTIs or NRTIs was detected since week $48 .{ }^{44}$ In this randomized double-blind study, DTG has shown a similar efficacy, tolerability, and safety profile to another first-line INSTI. ${ }^{44}$

The FLAMINGO study ${ }^{45}$ is a multicenter, open-label, Phase IIIb, noninferiority study. Treatment-naïve adults with HIV-1 infection were randomly assigned (1:1) to receive 
$50 \mathrm{mg}$ of DTG once daily or $800 \mathrm{mg}$ of DRV plus $100 \mathrm{mg}$ of RTV100 once daily, with investigator-selected TDF/FTC or ABC/3TC. No study participants had primary reverse transcriptase or protease mutations upon enrolment, and all had a viral load above 1,000 copies. The primary endpoint was the proportion of patients with HIV-1 RNA concentration $<50$ copies $/ \mathrm{mL}$ at week 48 with a $12 \%$ noninferiority margin.

Analysis at week 48 showed $90 \%$ of patients in the DTG arm and $83 \%$ of patients on the DRV plus RTV arm had HIV-1 RNA of $<50$ copies/mL. The adjusted difference of $7.1 \%$ (95\% CI: $0.9 \%-13.2 \%$ ) confirmed the superiority of DTG to DRV/RTV in antiretroviral-naïve adults $(P=0.025)$. Virological failure was similar in both arms, with no treatment-emergent resistance recorded in either group. Median CD4 gain was similar in both treatment arms. Results, however, among those with baseline viral loads $>100,000$ copies $/ \mathrm{mL}$ favored DTG. There was less discontinuation due to AEs in the DTG arm (2\%) than for DRV plus RTV (4\%) and that may have contributed to the difference in response rates. Once-daily DTG was numerically and statistically superior to once-daily DRV plus RTV in patients with baseline viral load $>100,000$ copies/mL; however, those in the stratum below 100,000 copies results were quite comparable. In the FLAMINGO study, DTG demonstrated for the second time that it is superior to another recommended first-line antiretroviral agent. ${ }^{45}$

SAILING is a 48-week, Phase III, randomized, doubleblind, active-controlled, noninferiority study involving adults who are on failing antiretroviral therapy with ongoing viral replication, resistance to two or more classes of antiretroviral drugs, and had one to two fully active drugs for background therapy. ${ }^{46}$ They had not been previously exposed to INSTIs. Participants received $50 \mathrm{mg}$ of DTG once daily or $400 \mathrm{mg}$ of RAL twice daily, with investigator-selected background therapy. The primary endpoint was the proportion of patients with plasma HIV-1 RNA $<50$ copies/mL at week 48, while secondary endpoint was the proportion of patients with treatment-emergent INSTIs resistance. At week 48 of followup, $71 \%$ of patients on DTG had HIV-1 RNA $<50$ copies $/ \mathrm{mL}$ versus $64 \%$ of patients on RAL (adjusted difference $7.4 \%$, 95\% CI: 0.7-14.2); confirming superiority of DTG against RAL $(P=0.03)$. Significantly fewer patients had virological failure with treatment-emergent INSTIs resistance on DTG (four vs 17 patients; adjusted difference $-3.7 \%$, 95\% CI: -6.1 to $-1.2 ; P=0.003)$. AE frequencies were similar across both groups. Once-daily DTG had greater virological efficacy compared to twice-daily RAL in this treatment-experienced patient group and was well tolerated. The statistical superiority demonstrated in the DTG arm was driven by fewer withdrawals due to lack of efficacy, lower number of protocol-defined virological failures, and lower treatmentemergent resistance.

The safety and efficacy of DTG in treatment-experienced subjects with RAL-resistant HIV-1 infection have been assessed in the VIKING study. ${ }^{47}$ In this study, individuals received $50 \mathrm{mg}$ of DTG once daily (Cohort I) or $50 \mathrm{mg}$ twice daily (Cohort II) while continuing the failing regimen (without RAL). After day 10, the background regimen was optimized where feasible for Cohort I and at least one fully active drug was mandated for Cohort II. The primary endpoint was the proportion of subjects on day 11 with $\geq 0.7 \log 10$ copies/mL plasma HIV-1 RNA reduction below baseline or $<400$ copies/mL. Ninety-six percent of subjects in Cohort II and 78\% of subjects in Cohort I achieved the primary end point (ie, a reduction in plasma HIV-1 RNA level of $\geq 0.7 \log 10$ copies $/ \mathrm{mL}$ below the baseline value or a level of $<400$ copies/mL on day 11 . Fifty-four percent in Cohort II and 41\% in Cohort I achieved an HIV-1 RNA level of $<400$ copies/mL on day $11 .{ }^{47}$ At week 24 , the response rate was greater in Cohort II, 75\% had a plasma HIV-1 RNA level of $<50$ copies $/ \mathrm{mL}$, in contrast to $41 \%$ in Cohort I. ${ }^{47}$ The response rates increased in both cohorts as the number of fully active agents in the optimized background regimen was added.

DTG has also been assessed in antiretroviral-experienced patients with RAL- and/or EVG-resistant HIV-1: VIKING-3 $3^{48}$ and VIKING-4 ${ }^{49}$ study (Table 2). VIKING-3 is a single-arm, open-label Phase III study in which INSTIs-experienced adults with INSTI-resistant virus received DTG $50 \mathrm{mg}$ twice daily while continuing their failing regimen (without RAL or EVG and resistance to $\geq 2$ ART classes other than INSTIs). Through day 7 , the regimen was optimized with one or more fully active drug and DTG continued. Over the 8-day monotherapy period, it was obvious that DTG demonstrated activity against viruses that have INSTI resistance. ${ }^{44}$ The greatest result was seen in those with a history of INSTI resistance but no INSTI resistance mutations at baseline. These patients had a drop in HIV-1 RNA of $1.5 \log 10$ copies/mL $(P<0.001)$. At week $24,74 \%$ of patients had viral loads below 400 copies $/ \mathrm{mL}$ and response maintained at week 48 . Those who had one INSTI mutation with Q148 still had a good response, but slightly less than those with no mutations. However, the effect was reduced when Q148 was paired with $\geq 2$ INSTI mutations. Safety profile on DTG $50 \mathrm{mg}$ twice daily was similar to that with DTG $50 \mathrm{mg}$ once daily. ${ }^{45,46}$ Another study ${ }^{50}$ has investigated 
whether DTG-resistant viruses are impaired in their ability to acquire further resistance to other agents such as NRTIs and NNRTIs as a consequence of their relative inability to develop resistance mutations associated with these two compounds. In this study, ${ }^{50}$ the investigators examined the ability of DTG-resistant viruses containing either the R263K or G118R and/or H51Y mutations to develop further resistance against several reverse transcriptase inhibitors during in vitro selection experiments. The investigators were able to show that mutations in the $\mathrm{R} 263 \mathrm{~K}$ and G118R resistance pathways delay the emergence of resistance mutations against reverse transcriptase inhibitor and suggest that the presence of mutations associated with resistance to DTG can impair the ability of HIV to acquire further resistance against nevirapine and 3TC, a NNRTI, and NRTI, respectively. ${ }^{50}$ These findings may be in line with the conception that R263K may not be a deleterious mutation for DTG in contrast to the mutations in the RAL/EVG pathways that have the ability to severely compromise DTG activity. ${ }^{50}$

The recently presented data by Granier et $\mathrm{al}^{51}$ from pooled analysis of three different naïve studies (SINGLE, SPRING-2, and FLAMINGO) have demonstrated the superiority of virological efficacy over comparator in two of the three-naïve studies. These pooled analyses suggested no evidence of a difference in long-term virological efficacy between DTG and third agents or between $\mathrm{ABC} / 3 \mathrm{TC}$ and TDF/FTC at low or high viral load.

\section{Resistance}

DTG has been considered to have a higher genetic barrier and minimal cross-resistance compared to other INSTIs. ${ }^{52}$ The major mutations that reduced DTG antiviral efficacy in vitro were I151L, T66K/L74M, G140/Q148R, G140/G148R, and E138K/Q148R. There was an increase in susceptibility from 3.5- to 8.4-fold change in susceptibility, but the isolates still retain the susceptibility to DTG. The combination of mutations at E138K and Q148R results in a tenfold decrease in DTG susceptibility compared to a 140-330-fold susceptibility to RAL and 370-390-fold susceptibility to EVG. ${ }^{51}$ These data suggest that DTG may still retain antiviral activity against virus resistant to other two INSTIs. Underwood et al has shown that patients failing with RAL with mutations at Y143 or N155 can retain activity with DTG. ${ }^{53}$ But those with Q148 and additional INSTI mutations should decrease susceptibility to DTG. There are few other mutations like H51Y, which potentially may reduce DTG activity but they are very rare and unlikely to appear and further studies may delineate more information. The resistance data from the available clinical studies have so far shown that multiple IN mutations plus a mutation at Q148 are necessary to reduce DTG activity. ${ }^{54-56}$ In the presence of INSTI resistance, the dose of DTG should be increased to $50 \mathrm{mg}$ twice daily as has been used in VIKING-3 $3^{48}$ and VIKING-4 ${ }^{49}$ studies.

\section{Dolutegravir: adverse effects, safety, and tolerability}

DTG has revealed a favorable safety profile in Phases II and III trials (Table 3). In the SPRING-1 study, there were no doserelated patterns in type, frequency, or severity of AEs across DTG doses, and most events reported in the DTG groups were of mild (48\%) or moderate $(34 \%)$ intensity. Only $2 \%$ of individuals in the SINGLE trial withdrew from the DTG arm due to AEs, compared to $10 \%$ from the EFV arm. ${ }^{41,42}$ In SPRING-2, DTG and RAL were equally tolerated with only ten patients $(2 \%)$ in each group discontinuing because of AEs. No study-related serious AEs occurred between week 48 and week 96. Nausea, headache, diarrhea, and sleep disturbances were the most common AEs being reported by individuals taking DTG (Table 3). Blood levels of DTG in the randomized clinical trials ${ }^{56}$ were not correlated with the presence of the most frequent AEs, including diarrhea, nausea, and headache or with most clinical laboratory tests of interest. ${ }^{43,57,58}$ The most common laboratory abnormalities reported in the clinical trials were increased cholesterol (Figure 1), lipase, bilirubin, aspartate transaminase/alanine transaminase, creatine phosphokinase, and prothrombin time, as well as decreased phosphate and neutrophil count. ${ }^{41,42,56}$ Patients with underlying hepatitis B or C may be at increased risk of worsening or development of transaminase elevations with the use of

Table 3 Dolutegravir adverse effects grades $2-4$ in treatmentnaïve trials

\begin{tabular}{|c|c|c|}
\hline Side effects & Range (\%) & Comments \\
\hline Gastro & $2-17$ & $\begin{array}{l}\text { Diarrhea and nausea were the most } \\
\text { common Gl side effects, mainly mild- } \\
\text { to-moderate in severity }\end{array}$ \\
\hline Headache & $1-15$ & Mainly mild in nature \\
\hline Insomnia & $1-4$ & Were typically mild in intensity \\
\hline Rash & 1 & $\begin{array}{l}\text { Were significantly low in most of the } \\
\text { studies (generalized macular rash, } \\
\text { maculopapular rash, pruritic rash) }\end{array}$ \\
\hline Liver abnormality & $2-3$ & $\begin{array}{l}\text { Alternative causes for raised ALT } \\
\text { identified in few patients. Very few } \\
\text { patients had DTG-associated DILI } \\
\text { with hypersensitivity reaction }\end{array}$ \\
\hline Nasopharyngitis & $<1$ & Mild in nature \\
\hline
\end{tabular}

Note: Data from the following studies. ${ }^{41-45}$

Abbreviations: DTG, dolutegravir; DILI, drug-induced liver injury; GI, gastrointestinal; ALT, alanine transaminase. 


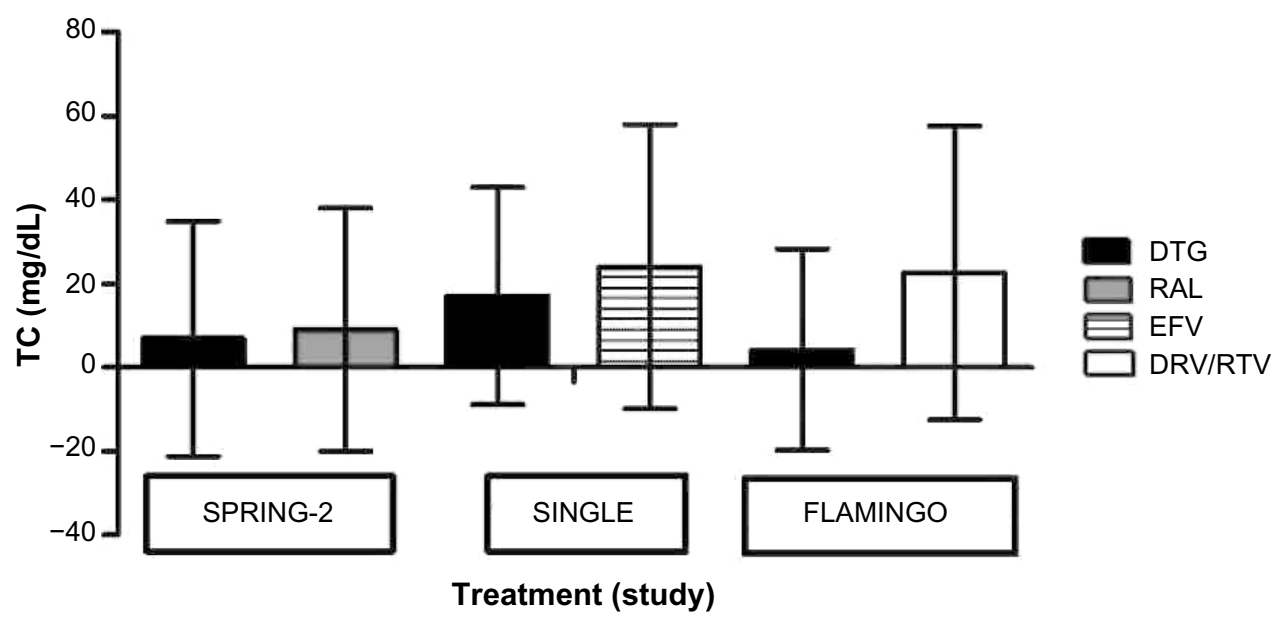

Figure I Mean TC changes from baseline at 48 weeks.

Abbreviations: DRV/RTV, darunavir/ritonavir; DTG, dolutegravir; EFV, efavirenz; RAL, raltegravir; TC, total cholesterol.

DTG. In some cases, the elevations in transaminases were consistent with immune reconstitution syndrome or hepatitis $\mathrm{B}$ reactivation, particularly in the setting where antihepatitis therapy was withdrawn. The AEs did not appear to be related to plasma DTG exposure.

Overall, DTG is well tolerated, with headache and insomnia being the most frequently reported AEs. A systematic review by Patel et $\mathrm{al}^{59}$ has demonstrated that DTG use was associated with a relatively lower risk of AEs and less risk of withdrawal from studies due to AEs compared to other antiretrovirals including EFV, boosted PIs, but no difference compared to RAL and rilpivirine use (Table 3).

Hypersensitivity reactions have been reported in $<1 \%$ of subjects receiving DTG in Phase III randomized controlled clinical trials. ${ }^{41,42}$ More over DTG when used in a combination product with $\mathrm{ABC}$ and $3 \mathrm{TC}$ marketed as triumeq has the potential to have hypersensitivity reactions as seen in $\mathrm{ABC}$ use alone. Clinically, it is unlikely to be differentiated whether the reaction is due to $\mathrm{ABC}$ or $\mathrm{DTG}$.

\section{Effect of dolutegravir on lipids}

DTG appears to be lipid neutral. In comparative analysis from the SINGLE, SPRING-2, and FLAMINGO studies, DTG demonstrated a generally neutral effect on serum lipid changes irrespective of nucleoside backbone (Figures 1-4). ${ }^{59,60}$ The total cholesterol/high-density lipoprotein ratio remained similar in all the groups (Figure 5). This is comparable to the similar effect seen with other INSTIs, namely, RAL. In a systematic review, Patel et al ${ }^{59}$ showed that DTG use was associated with lower rise of total cholesterol, low-density lipoprotein cholesterol, and triglyceride compared to EFV and boosted PIs, including ATV, DRV, and LPV. ${ }^{60}$

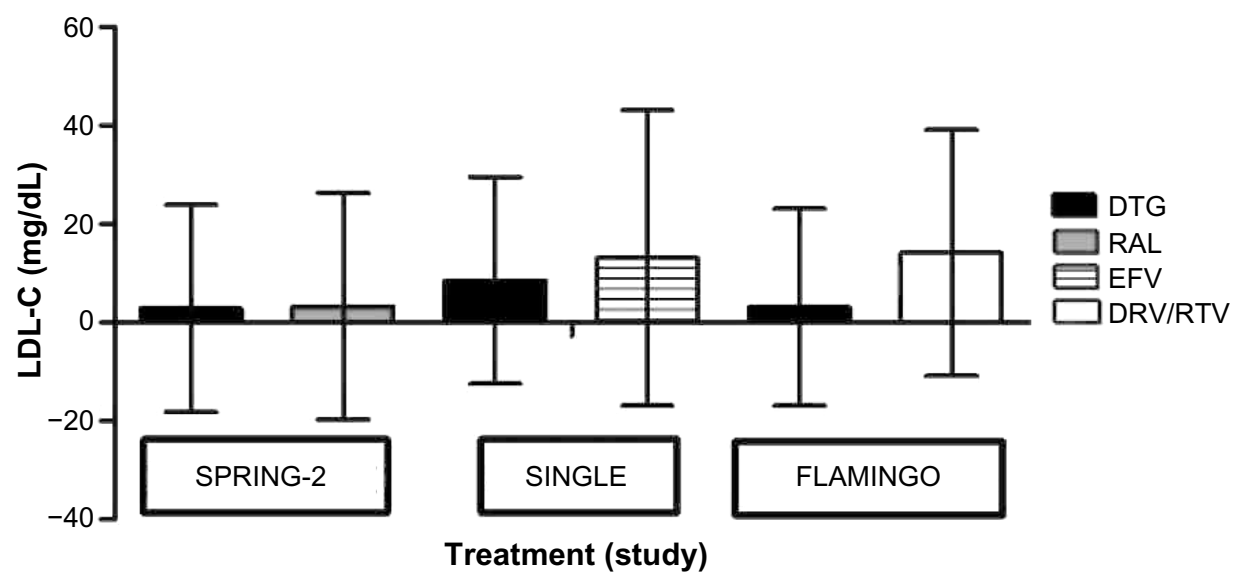

Figure 2 Mean LDL-C changes from baseline at 48 weeks.

Abbreviations: DRV/RTV, darunavir/ritonavir; DTG, dolutegravir; EFV, efavirenz; LDL-C, low-density lipoprotein cholesterol; RAL, raltegravir. 


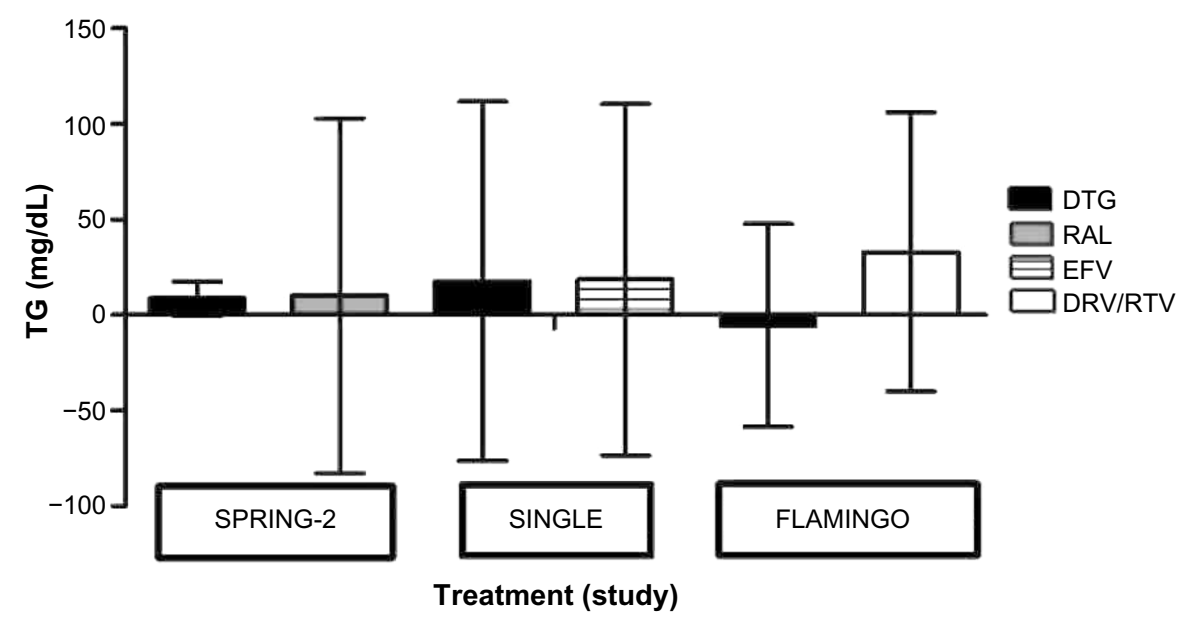

Figure 3 Mean TG changes from baseline at 48 weeks.

Abbreviations: DRV/RTV, darunavir/ritonavir; DTG, dolutegravir; EFV, efavirenz; RAL, raltegravir; TG, triglyceride.

\section{Effect on bone health}

DTG like other INSTIs appears to have less effect on bone health. In SINGLE study after 48 weeks of follow-up, bone markers were increased in both groups, but the increases were significantly higher in the Atripla group. Vitamin-D levels are decreased in both the arms, but the differences were not different. ${ }^{61}$ The BMD changes as demonstrated by DEXA scan did not reveal any difference in DTG use. ${ }^{61}$ Recently presented data from the study after 144 weeks of follow-up have shown an increased turnover of bone markers in the Atripla arm compared to the DTG arm. Vitamin-D levels were similar in both groups. ${ }^{62}$

\section{Use in special population}

DTG so far appeared to be safe and well tolerated in both treatment-naïve and treatment-experienced patients. In the absence of more robust information, caution should be taken in specific populations (Table 4).

\section{Dolutegravir - patient perspectives quality of life, patient satisfaction and acceptability, adherence}

There are important factors to think of when deciding whether a given regimen should be considered a "recommended" option for a first-line therapy such as efficacy, tolerability, and convenience of taking the drug, which all play important roles. ${ }^{3}$ This also includes, drug-drug and drug-food interactions, as well as baseline patient-specific factors such as CD4+ cell count, ${ }^{3}$ plasma HIV-1 RNA level, child-bearing potential (in women), and a range of comorbidities, including viral hepatitis coinfection. ${ }^{63}$ All three INSTIs are now included within the treatment guidelines for

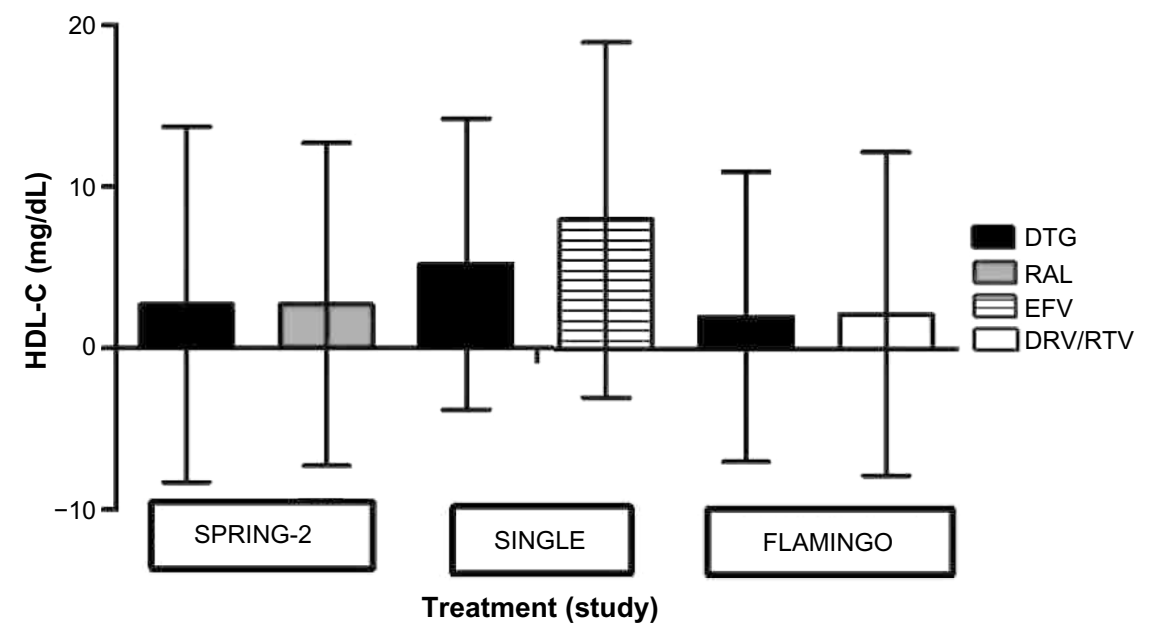

Figure 4 Mean HDL-C changes from baseline at 48 weeks.

Abbreviations: DRV/RTV, darunavir/ritonavir; DTG, dolutegravir; EFV, efavirenz; HDL-C, high-density lipoprotein cholesterol; RAL, raltegravir. 


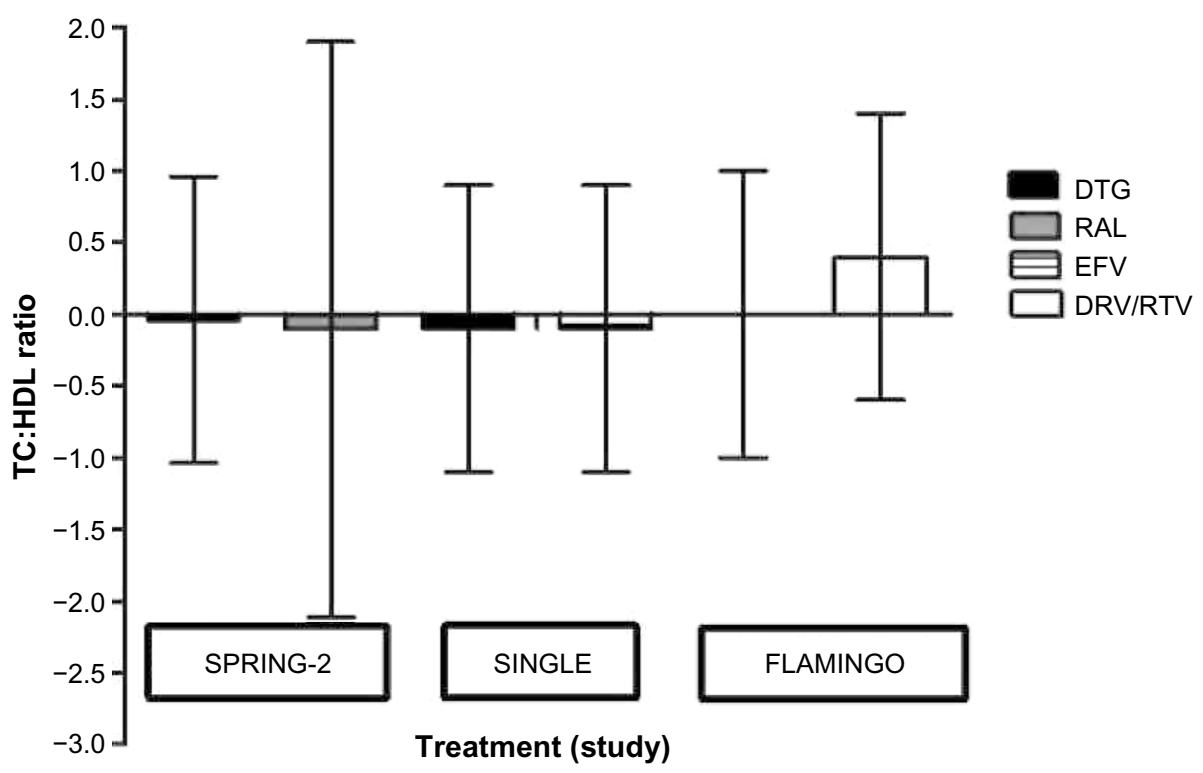

Figure 5 TC:HDL ratio changes from baseline at 48 weeks.

Abbreviations: DRV/RTV, darunavir/ritonavir; DTG, dolutegravir; EFV, efavirenz; RAL, raltegravir; TC:HDL, total cholesterol:high-density lipoprotein.

the adult HIV patients. ${ }^{3}$ In randomized controlled studies, DTG has shown superiority over two other commonly used third agents, EFV and boosted DRV. DTG has a novel resistance profile, it has shown activity against HIV-1 isolates with INSTI-resistant strains with no emergent resistance to date with first-line DTG failure. DTG is metabolized by UGT1A, with minimal contribution from cytochrome P450 (3A4 isoform) and limiting DDI. ${ }^{11}$ DTG has a prolonged intracellular half-life; thus, once-daily dosing without the need for pharmacological booster is acceptable if taken with or without food. ${ }^{8,11}$ INSTIs are potent agents, well tolerated with favorable metabolic profiles and few DDIs (RAL, DTG). Despite the rates of transmitted (baseline) drug resistance to INSTIs alleged to be low, resistant phenotypes have been reported for both RAL and EVG. ${ }^{64}$ Certain mutations confer cross-resistance between both agents (RAL and EVG), but DTG has a better resistance profile and so far appears to have relatively higher genetic barriers. ${ }^{46,65}$

Pill burden, twice daily regimen, relation of food and content of food, taking pills at particular time of the day had all been factors with antiretrovirals. ${ }^{66,67}$ DTG has the potential to overcome all these barriers and can be taken once daily as a single pill at any time of the day without the need for food. This has the potential advantage of giving patients the liberty to take medications at their choice, not compromising with their daily life promising a better quality of life. Moreover, HIV patients are living longer and when polypharmacy is common in patients in aged

Table 4 Use of dolutegravir in special population

\begin{tabular}{|c|c|c|}
\hline Conditions & Findings & Comment \\
\hline Pregnancy & $\begin{array}{l}\text { Categorized as pregnancy category } B \text {. No adequate and well-controlled studies in } \\
\text { pregnant women because animal reproduction studies are not always predictive } \\
\text { of human response. }\end{array}$ & To be used with caution. \\
\hline Nursing mother & In animal studies DTG was present in rat milk, human data are not available. ${ }^{72}$ & No clear evidence. \\
\hline Pediatric & $\begin{array}{l}\text { Safety and efficacy of use of DTG has not been established in pediatric patients } \\
\text { younger than } 12 \text { years and weighing }<40 \mathrm{~kg} \text {. }\end{array}$ & No clear evidence. \\
\hline Elderly & The data of safety in patients aged over 65 years is very limited. & To be used with caution. \\
\hline Renal & $\begin{array}{l}\text { The plasma concentration of DTG was found to be decreased in subjects with } \\
\text { severe renal impairment compared to those in the healthy controls; however, no } \\
\text { dose adjustment was necessary where renal impairment was mild-to-moderate. }{ }^{73,74} \\
\text { No data on renal dialysis patients. }\end{array}$ & $\begin{array}{l}\text { Caution in severe renal } \\
\text { impairment. }\end{array}$ \\
\hline Hepatic & $\begin{array}{l}\text { There have not been any differences between subjects with moderate hepatic } \\
\text { impairment and hepatic subjects. } .^{63,75,76}\end{array}$ & $\begin{array}{l}\text { No dose adjustment in mild or } \\
\text { moderate hepatic impairment. }\end{array}$ \\
\hline Hepatitis B and C coinfection & DTG can be safely used with boceprevir and telaprevir. ${ }^{30,63}$ & No dose adjustment. \\
\hline
\end{tabular}
Abbreviation: DTG, dolutegravir. 
population, ${ }^{68}$ less pill burden and minimal drug interaction appears to be a distinct advantage of DTG compared to others. ${ }^{69}$ The debate of using DTG with ABC in patients with high-risk cardiovascular disease remains and that has to be dealt with on an individual patient level. ${ }^{70,71}$ INSTI-based regimens may be appropriate for many (if not most) treatment-naïve patients and DTG represents a new option for INSTIs-experienced patients.

\section{Conclusion}

DTG is an INSTI that maintains a high plasma level and supports a once-daily dosing regimen without the need for a pharmacokinetic boosting agent. DTG in combination with $\mathrm{ABC}$ and $3 \mathrm{TC}$ has developed a single-tablet regimen for the treatment of HIV infection. Such treatment could have the potential to be advantageous over the other combination antiretroviral agents available as a single tablet. As there is very minimal effect on Phase I liver metabolism involving CYP-pathway, it is unlikely to interact with other antiretroviral agents and a very minimum interaction with other commonly used medicinal agents.

Although there is potential for the interaction at renal tubular level involving OCTP, the clinical significance so far appeared to be very minimum. DTG, the third INSTI, appears comparable to or better than guideline-approved first-line antiretroviral agents with potent antiviral activity. DTG remains the agent with good tolerability and better patient safety. It has multiple clearance pathways and little clinically significant pharmacokinetic variability, and it has also a predictable exposure-response relationship. DTG has the advantage of being a once-daily tablet, with a small milligram dose and tablet size. Although the size of the combination tablet containing DTG, ABC, and 3TC named as triumeq is not smaller than the available single-pill regimen, it has been well tolerated in all the randomized control trials and appeared to be safe and effective. DTG has the potential to become the first-line antiretroviral agent, with a strong prospect of offering a good quality of life for the patients.

\section{Author contributions}

HT and SD jointly did the literature search and appraised the papers. HT prepared the first draft. AD did further literature search, revised the paper, and helped in citations and preparing the tables and figures. SD conceived the idea and supervised the whole paper. All authors contributed toward data analysis, drafting and critically revising the paper and agree to be accountable for all aspects of the work.

\section{Disclosure}

The authors report no conflicts of interest in this work.

\section{References}

1. Wei X, Ghosh SK, Taylor ME, et al. Viral dynamics in human immunodeficiency virus type 1 infection. Nature. 1995;373(6510):117-122.

2. Brass AL, Dykxhoorn DM, Benita Y, et al. Identification of host proteins required for HIV infection through a functional genomic screen. Science. 2008;319(5865):921-926.

3. Williams I, Churchill D, Anderson J, et al. British HIV Association guidelines for the treatment of HIV-1-positive adults with antiretroviral therapy 2012. HIV Med. 2012;13(Suppl 2):1-85.

4. Khatib N, Das S. PRO 140 - a novel CCR5 co-receptor inhibitor. Recent Pat Antiinfect Drug Discov. 2010;5(1):18-22.

5. Das S. Lipid Disorder in HIV Infection: Apolipoprotein-B Kinetics, Fat Distribution, Insulin Resistance and Adipocytokines in Patients Taking Protease Inhibitors or Non-Nucleoside Reverse Transcriptase Inhibitors. University of Birmingham; 2010. Available from: http:// etheses.bham.ac.uk/1475/.

6. [Integrase inhibitor in HIV therapy. Does dolutegravir set new standards?]. MMW Fortschr Med. 2014;156(Suppl 1):58-59.

7. Arribas JR, Eron J. Advances in antiretroviral therapy. Curr Opin HIV AIDS. 2013;8(4):341-349.

8. Adams JL, Greener BN, Kashuba AD. Pharmacology of HIV integrase inhibitors. Curr Opin HIV AIDS. 2012;7(5):390-400.

9. Taha H, Morgan J, Das A, Das S. Parenteral patent drug S/GSK1265744 has the potential to be an effective agent in pre-exposure prophylaxis against HIV infection. Recent Pat Antiinfect Drug Discov. 2013;8(3): 213-218.

10. Koh Y, Wu X, Ferris AL, et al. Differential effects of human immunodeficiency virus type 1 capsid and cellular factors nucleoporin 153 and LEDGF/p 75 on the efficiency and specificity of viral DNA integration. J Virol. 2013;87(1):648-658.

11. Cottrell ML, Hadzic T, Kashuba AD. Clinical pharmacokinetic, pharmacodynamic and drug-interaction profile of the integrase inhibitor dolutegravir. Clin Pharmacokinet. 2013;52(11):981-994.

12. Hare S, Smith SJ, Metifiot M, et al. Structural and functional analyses of the second-generation integrase strand transfer inhibitor dolutegravir (S/GSK1349572). Mol Pharmacol. 2011;80(4):565-572.

13. Adams JL, Patterson KB, Prince HM, et al. Single and multiple dose pharmacokinetics of dolutegravir in the genital tract of HIV-negative women. Antivir Ther. 2014;18(8):1005-1013.

14. Song I, Borland J, Chen S, et al. Effect of food on the pharmacokinetics of the integrase inhibitor dolutegravir. Antimicrob Agents Chemother. 2012;56(3):1627-1629.

15. Castellino S, Moss L, Wagner D, et al. Metabolism, excretion, and mass balance of the HIV-1 integrase inhibitor dolutegravir in humans. Antimicrob Agents Chemother. 2013;57(8):3536-3546.

16. DeAnda F, Hightower KE, Nolte RT, et al. Dolutegravir interactions with HIV-1 integrase-DNA: structural rationale for drug resistance and dissociation kinetics. PLoS One. 2013;8(10):e77448.

17. Chen S, St Jean P, Borland J, et al. Evaluation of the effect of UGT1A1 polymorphisms on dolutegravir pharmacokinetics. Pharmacogenomics. 2014;15(1):9-16.

18. Gutierrez F, Fulladosa X, Barril G, Domingo P. Renal tubular transporter-mediated interactions of HIV drugs: implications for patient management. AIDS Rev. 2014;16(4):199-212.

19. Lepist EI, Zhang X, Hao J, et al. Contribution of the organic anion transporter OAT2 to the renal active tubular secretion of creatinine and mechanism for serum creatinine elevations caused by cobicistat. Kidney Int. 2014;86(2):350-357.

20. Koteff J, Borland J, Chen S, et al. A phase 1 study to evaluate the effect of dolutegravir on renal function via measurement of iohexol and paraaminohippurate clearance in healthy subjects. $\mathrm{Br} J$ Clin Pharmacol. 2013;75(4):990-996. 
21. Patel P, Song I, Borland J, et al. Pharmacokinetics of the HIV integrase inhibitor S/GSK1349572 co-administered with acid-reducing agents and multivitamins in healthy volunteers. J Antimicrob Chemother. 2011;66(7):1567-1572.

22. Crauwels H, van Heeswijk RP, Stevens M, et al. Clinical perspective on drug-drug interactions with the non-nucleoside reverse transcriptase inhibitor rilpivirine. AIDS Rev. 2013;15(2):87-101.

23. Song I, Borland J, Chen S, et al. Effects of enzyme inducers efavirenz and tipranavir/ritonavir on the pharmacokinetics of the HIV integrase inhibitor dolutegravir. Eur J Clin Pharmacol. 2014;70(10):1173-1179.

24. Song I, Borland J, Min S, et al. Effects of etravirine alone and with ritonavir-boosted protease inhibitors on the pharmacokinetics of dolutegravir. Antimicrob Agents Chemother. 2011;55(7):3517-3521.

25. Ford SL, Gould E, Chen S, et al. Lack of pharmacokinetic interaction between rilpivirine and integrase inhibitors dolutegravir and GSK1265744. Antimicrob Agents Chemother. 2013;57(11):5472-5477.

26. Song I, Min SS, Borland J, et al. The effect of lopinavir/ritonavir and darunavir/ritonavir on the HIV integrase inhibitor S/GSK1349572 in healthy participants. J Clin Pharmacol. 2011;51(2):237-242.

27. Song I, Borland J, Chen S, et al. Effect of atazanavir and atazanavir/ ritonavir on the pharmacokinetics of the next-generation HIV integrase inhibitor, S/GSK1349572. Br J Clin Pharmacol. 2011;72(1): 103-108.

28. Song I, Borland J, Arya N, Wynne B, Piscitelli S. Pharmacokinetics of dolutegravir when administered with mineral supplements in healthy adult subjects. J Clin Pharmacol. 2014;55(5):490-496.

29. Dooley KE, Sayre P, Borland J, et al. Safety, tolerability, and pharmacokinetics of the HIV integrase inhibitor dolutegravir given twice daily with rifampin or once daily with rifabutin: results of a phase 1 study among healthy subjects. J Acquir Immune Defic Syndr. 2013;62(1): 21-27.

30. Johnson M, Borland J, Chen S, Savina P, Wynne B, Piscitelli S. Effects of boceprevir and telaprevir on the pharmacokinetics of dolutegravir. Br J Clin Pharmacol. 2014;78(5):1043-1049.

31. Yeh W, Feng H-P, Guo Z, et al. Drug-drug interaction between HCV inhibitors grazoprevir/elbasvir with dolutegravir. In: Conference on Retrovirus and Opportunistic Infection; 2015; Seattle, USA.

32. Song IH, Borland J, Chen S, Wajima T, Peppercorn AF, Piscitelli SC Dolutegravir has no effect on the pharmacokinetics of oral contraceptives with norgestimate and ethinyl estradiol. Ann Pharmacother. 2015;49(7): 784-789.

33. Drew BJ, Ackerman MJ, Funk M, et al. Prevention of torsade de pointes in hospital settings: a scientific statement from the American Heart Association and the American College of Cardiology Foundation. J Am Coll Cardiol. 2010;55(9):934-947.

34. Min S, Song I, Borland J, et al. Pharmacokinetics and safety of S/GSK1349572, a next-generation HIV integrase inhibitor, in healthy volunteers. Antimicrob Agents Chemother. 2010;54(1): 254-258.

35. Gillette MA, Shah BM, Schafer JJ, DeSimone JA Jr. Dolutegravir: a new integrase strand transfer inhibitor for the treatment of HIV - an alternative viewpoint. Pharmacotherapy. 2014;34(9):e173-e174.

36. Reese MJ, Savina PM, Generaux GT, et al. In vitro investigations into the roles of drug transporters and metabolizing enzymes in the disposition and drug interactions of dolutegravir, a HIV integrase inhibitor. Drug Metab Dispos. 2013;41(2):353-361.

37. Zong J, Borland J, Jerva F, Wynne B, Choukour M, Song I. The effect of dolutegravir on the pharmacokinetics of metformin in healthy subjects. J Int AIDS Soc. 2014;17(4 Suppl 3):19584.

38. Song IH, Borland J, Chen S, Savina P, Peppercorn AF, Piscitelli S. Effect of prednisone on the pharmacokinetics of the integrase inhibitor dolutegravir. Antimicrob Agents Chemother. 2013;57(9):4394-4397.

39. Information D. Dolutegravir Tablet; 2015. Available from: http://www. druginformation.com/RxDrugs/D/Dolutegravir\%20Tablets.html.

40. Song I, Mark S, Chen S, et al. Dolutegravir does not affect methadone pharmacokinetics in opioid-dependent, HIV-seronegative subjects. Drug Alcohol Depend. 2013;133(2):781-784.
41. van Lunzen J, Maggiolo F, Arribas JR, et al. Once daily dolutegravir (S/GSK1349572) in combination therapy in antiretroviral-naive adults with HIV: planned interim 48 week results from SPRING-1, a dose-ranging, randomised, phase 2 b trial. Lancet Infect Dis. 2012;12(2): $111-118$.

42. Walmsley SL, Antela A, Clumeck N, et al. Dolutegravir plus abacavirlamivudine for the treatment of HIV-1 infection. $N$ Engl J Med. 2013;369(19):1807-1818.

43. Raffi F, Rachlis A, Brinson C, et al. Dolutegravir efficacy at 48 weeks in key subgroups of treatment-naive HIV-infected individuals in three randomized trials. AIDS. 2015;29(2):167-174.

44. Raffi F, Jaeger H, Quiros-Roldan E, et al. Once-daily dolutegravir versus twice-daily raltegravir in antiretroviral-naive adults with HIV-1 infection (SPRING-2 study): 96 week results from a randomised, double-blind, non-inferiority trial. Lancet Infect Dis. 2013;13(11):927-935.

45. Clotet B, Feinberg J, van Lunzen J, et al. Once-daily dolutegravir versus darunavir plus ritonavir in antiretroviral-naive adults with HIV-1 infection (FLAMINGO): 48 week results from the randomised open-label phase 3b study. Lancet. 2014;383(9936):2222-2231.

46. Cahn P, Pozniak AL, Mingrone H, et al. Dolutegravir versus raltegravir in antiretroviral-experienced, integrase-inhibitor-naive adults with HIV: week 48 results from the randomised, double-blind, non-inferiority SAILING study. Lancet. 2013;382(9893):700-708.

47. Eron JJ, Clotet B, Durant J, et al. Safety and efficacy of dolutegravir in treatment-experienced subjects with raltegravir-resistant HIV type 1 infection: 24-week results of the VIKING study. J Infect Dis. 2013;207(5):740-748.

48. Castagna A, Maggiolo F, Penco G, et al. Dolutegravir in antiretroviralexperienced patients with raltegravir- and/or elvitegravir-resistant HIV-1: 24-week results of the phase III VIKING-3 study. J Infect Dis. 2014;210(3):354-362.

49. Akil B, Blick G, Hagins DP, et al. Dolutegravir versus placebo in subjects harbouring HIV-1 with integrase inhibitor resistance associated substitutions: 48-week results from VIKING-4, a randomized study. Antivir Ther. 2015;20(3):343-348.

50. Oliveira M, Mesplede T, Quashie PK, Moisi D, Wainberg MA. Resistance mutations against dolutegravir in HIV integrase impair the emergence of resistance against reverse transcriptase inhibitors. AIDS. 2014;28(6):813-819.

51. Granier C, Givens N, Cuffe R, et al. Consistency of dolutegravir treatment difference in HIV+ treatment naives at week 96. In: Conference on Retrovirus and Opportunistic Infection; 2015; Seattle, USA.

52. Armenia D, Fabeni L, Alteri C, et al. HIV-1 integrase genotyping is reliable and reproducible for routine clinical detection of integrase resistance mutations even in patients with low-level viraemia. J Antimicrob Chemother. 2015;70(6):1865-1873.

53. Underwood MR, Johns BA, Sato A et al. The activity of the integrase inhibitor dolutegravir against HIV-1 variants isolated from raltegravirtreated adults. J Acquir Immune Defic Syndr. 2012;61(3):297-301.

54. Bessong PO, Nwobegahay J. Genetic analysis of HIV-1 integrase sequences from treatment naive individuals in Northeastern South Africa. Int J Mol Sci. 2013;14(3):5013-5024.

55. Bastarache SM, Mesplede T, Donahue DA, Sloan RD, Wainberg MA. Fitness impaired drug resistant HIV-1 is not compromised in cell-to-cell transmission or establishment of and reactivation from latency. Viruses. 2014;6(9):3487-3499.

56. Blake M, Sonia V. Dolutegravir: a new HIV integrase inhibitor for the treatment of HIV infection. Future Virol. 2015;9(11):967-978.

57. Boyd MA, Cooper DA. SPRING-2 the future of antiretroviral therapy. Lancet Infect Dis. 2013;13(11):908-909.

58. McCormack PL. Dolutegravir: a review of its use in the management of HIV-1 infection in adolescents and adults. Drugs. 2014;74(11): 1241-1252.

59. Patel DA, Snedecor SJ, Tang WY, et al. 48-Week efficacy and safety of dolutegravir relative to commonly used third agents in treatment-naive HIV-1-infected patients: a systematic review and network meta-analysis. PLoS One. 2014;9(9):e105653. 
60. Quercia R, Roberts J, Martin-Carpenter L, Zala C. Comparative changes of lipid levels in treatment-naive, HIV-1-infected adults treated with dolutegravir vs efavirenz, raltegravir, and ritonavirboosted darunavir-based regimens over 48 weeks. Clin Drug Investig. 2015;35(3):211-219.

61. Tebas P, Kumar P, Hicks C, et al. 48 Week bone marker changes in dolutegravir (DTG; GSK1349572) plus abacavir/lamivudine (ABC/3TC) vs tenofovir/emtricitabine/efavirenz (EFV/TDF/FTC): the SINGLE trial. In: 53rd Interscience Conference on Antimicrobial Agents and Chemotherapy; 2013; Denver, USA.

62. Tebas P, Quercia Q, Paice A, et al. SINGLE W144: greater changes in bone turnover markers in antiretroviral therapy-naïve individuals initiating efavirenz/emtricitabine/tenofovir disoproxil fumarate compared with dolutegravir plus abacavir/lamivudine. Poster presented at: 21 st Annual Conference of the British HIV Association (BHIVA); April 21-24, 2015; Brighton, UK.

63. Nelson MR, Matthews G, Brook MG, Main J. BHIVA guidelines: coinfection with HIV and chronic hepatitis $\mathrm{C}$ virus. HIV Med. 2003;4(Suppl 1):52-62.

64. Stekler JD, McKernan J, Milne R, et al. Lack of resistance to integrase inhibitors among antiretroviral-naive subjects with primary HIV-1 infection, 2007-2013. Antivir Ther. 2015;20(1):77-80.

65. Frantzell A, Petropoulos CJ, Huang W. Dolutegravir resistance requires multiple primary mutations in HIV-1 integrase. In: Conference on Retrovirus and Opportunistic Infection; 2015; Seattle, USA.

66. Nachega JB, Parienti JJ, Uthman OA, et al. Lower pill burden and oncedaily antiretroviral treatment regimens for HIV infection: a meta-analysis of randomized controlled trials. Clin Infect Dis. 2014;58(9):1297-1307.
67. Wu P, Johnson BA, Nachega JB, et al. The combination of pill count and self-reported adherence is a strong predictor of first-line ART failure for adults in South Africa. Curr HIV Res. 2014;12(5):366-375.

68. Gimeno-Gracia M, Crusells-Canales MJ, Javier Armesto-Gomez F, Rabanaque-Hernandez MJ. Prevalence of concomitant medications in older HIV+ patients and comparison with general population. HIV Clin Trials. 2015;16(3):117-124.

69. Patel R, Moore T, Cooper V, et al. An observational study of comorbidity and healthcare utilisation among HIV-positive patients aged 50 years and over. Int J STD AIDS. Epub 2015 Jun 10.

70. Das S. Risk of cardiovascular disease in HIV-infected patients. J Antimicrob Chemother. 2010;65(3):386-389.

71. Das S. Evaluation of cardiovascular risk in HIV patients: clinical implication. Int J Clin Pract. 2010;64(9):1173-1175.

72. Pain JB, Le MP, Caseris M, et al. Pharmacokinetic of dolutegravir in a premature neonate after HIV treatment intensification during pregnancy. Antimicrob Agents Chemother. 2015;59(6):3660-3662.

73. Weller S, Borland J, Chen S, et al. Pharmacokinetics of dolutegravir in HIV-seronegative subjects with severe renal impairment. Eur J Clin Pharmacol. 2014;70(1):29-35.

74. Lee FJ, Carr A. Tolerability of HIV integrase inhibitors. Curr Opin HIV AIDS. 2012;7(5):422-428.

75. Miller MM, Liedtke MD, Lockhart SM, Rathbun RC. The role of dolutegravir in the management of HIV infection. Infect Drug Resist. 2015;8:19-29.

76. Surgers L, Lacombe K. Hepatoxicity of new antiretrovirals: a systematic review. Clin Res Hepatol Gastroenterol. 2013;37(2):126-133.
Infection and Drug Resistance

\section{Publish your work in this journal}

Infection and Drug Resistance is an international, peer-reviewed openaccess journal that focuses on the optimal treatment of infection (bacterial, fungal and viral) and the development and institution of preventive strategies to minimize the development and spread of resistance. The journal is specifically concerned with the epidemiology of antibiotic

\section{Dovepress}

resistance and the mechanisms of resistance development and diffusion in both hospitals and the community. The manuscript management system is completely online and includes a very quick and fair peerreview system, which is all easy to use. Visit http://www.dovepress.com/ testimonials.php to read real quotes from published authors. 